\title{
RADIATION EFFECTS ON HEAT AND MASS TRANSFER OF A MHD NANO FLUID
}

\author{
G. V. P. N. Srikanth ${ }^{1}$, G.Srinivas ${ }^{2}$, B. Tulasi Lakshmi Devi ${ }^{3}$, S. Sreenatha Reddy ${ }^{4}$ \\ ${ }^{I}$ Department of Mathematics, Guru Nanak Institute of Technology, Hyderabad, India \\ ${ }^{2}$ Department of Mathematics, Guru Nanak Institute of Technology, Hyderabad, India \\ ${ }^{3}$ Department of Mathematics, Guru Nanak Institute of Technology, Hyderabad, India \\ ${ }^{4}$ Department of Mechanical Engg, Guru Nanak Institute of Technology, Hyderabad, India
}

\begin{abstract}
The significant research saw with nano fluid flow and heat transfer. But, there was a wide scope of research in mass transfer with nano fluids, due to Brownian motion of particles. A theoretical investigation attempted in this paper to study the chemical reaction effects during mass transfer. We studied convective heat and mass transfer of MHD nano fluid flow past inclined, oscillating permeable flat plate with radiation and heat source. It is found that velocity and Diffusion increases for both kinds of chemical reactions.
\end{abstract}

Keywords: MHD Nano - fluid, Inclined plate, Radiation, Method of lines.

\section{INTRODUCTION}

The study of nano fluid has been attracting many researches since a few decades, due to its vital applications. The exponential growth of the study of nano fluids made the latest technology more convenient and user friendly.

As the nano-fluids carriey the metallic particle the heat transfer and diffusion together is a interesting phenomenon with wide application in the field of biomedical, drug delivery etc. Sarit Kumar Das et.al (7) studied that many researches could not explain the study of diffusivity. M.I Anwar et.al (6) studied the heat and mass transfer of nano fluids over a nonlinear stretching sheet for low constriction. Hyun UK Kang (2) studied the effect of Brownian motion and inertial migration of particles and concluded that the nano-particle migration to the center occurs slowly. Hence, the thermal conductivity at the walls increases. Many authors Buongiorno J (1), M. A. A. Hamad, I. Pop (5) Khan, W.A., A. Aziz (3), Kuznetsov AV, and Nield DA (4) studied the nano-fluid flow and heat transfer effects in various geometries and various effects. All the Researches used the Maxwell or Hamilton \& crosser model to describe the thermal conductivity of the nano fluid. In these models there was no description about the particle diameter or layer around the particle.

Many of the researches carried out and ignored the natural phenomenon of formation of liquid Like layer around nano particle because of the chemical reaction with the solvent. The formation of liquid like layer limited the contact of the metallic nano particle with the boundary. This reduced the effective heat transfer.
Keeping in view all the above fact we want to study the heat and mass transfer through copper And water nano fluid with chemical reaction over a permeable, inclined, and oscillating flat plate.

\section{MATHEMATICAL FORMULATION}

Consider the unsteady three dimensional free convection flow of a nano-fluid past a vertical permeable semi-infinite plate in the presence of an applied magnetic field with constant heat source and radiation. We consider a Cartesian coordinate system $(x, y, z)$.The flow assumes to be in the $x$ direction, which takes along the plate, and $z$ - axis is normal to the plate. We assume that the plate has an oscillatory movement on time $t$ and frequency $n$ with the velocity $\mathrm{u}(0, \mathrm{t})$, which gives $\mathrm{u}(0, \mathrm{t})=$ $\mathrm{U}_{0}(1+\varepsilon \cos (\mathrm{nt}))$, where $\varepsilon$ is a small constant parameter $(\varepsilon$ $<<1)$ and $U_{0}$ is the characteristic velocity. We consider that initially $(\mathrm{t}<0)$ the fluid as well as the plate is at rest. A uniform external magnetic field $\mathrm{B}_{0}$ takes to be acting along the $z$ - axis. We consider the case of a short circuit problem in which the applied electric field $\mathrm{E}=0$, and also assume that the induced magnetic field is small compared to the external magnetic field $\mathrm{B}_{0}$. The surface temperature assumes to have the constant value $\mathrm{T}_{\mathrm{W}}$ while the ambient temperature is the constant value $T_{\infty}$, where $T_{W}>T_{\infty}$. The conservation equation of current density $\nabla J=0$ gives $J_{Z}=$ constant. Since, the plate is electrically non-conducting, this constant is zero. It assumes that the plate is infinite in some extent. Hence, all physical quantities do not depend on $x$ and $y$ but depend only on $z$ and $t$,

$$
\text { i.e } \frac{\partial u}{\partial x}+\frac{\partial v}{\partial y}=0
$$


It assumes that the regular fluid and the suspended nanoparticles are in thermal equilibrium, no slip occurs between them. Under Bossinesq and boundary layer approximations, the boundary layer equations governing the flow and temperature are:

$$
\frac{\partial w}{\partial z}=0
$$

$\frac{\partial u}{\partial t}+w \frac{\partial u}{\partial z}=\frac{1}{\rho_{n f}}\left[\begin{array}{l}\mu_{n f} \frac{\partial^{2} u}{\partial z^{2}}+\left(\rho \beta_{T}\right)_{n f} g\left(T-T_{\infty}\right) \operatorname{Cos} \gamma \\ +\left(\rho \beta_{c}\right)_{n f} g\left(c-c_{\infty}\right) \operatorname{Cos} \gamma\end{array}\right]$

$\frac{\partial T}{\partial t}+w \frac{\partial T}{\partial z}=\alpha_{n f} \frac{\partial^{2} T}{\partial z^{2}}-\frac{Q}{\left(\rho c_{p}\right)_{n f}}\left(T-T_{\infty}\right)-\frac{1}{\left(\rho c_{p}\right)_{n f}} \frac{\partial q_{r}}{\partial z}$

$$
\frac{\partial c}{\partial t}+w \frac{\partial c}{\partial z}=D_{n f} \frac{\partial^{2} c}{\partial z^{2}}+k_{l}\left(c-c_{\infty}\right)
$$

The appropriate initial and boundary conditions for the problem is given by

$$
\begin{aligned}
& u(z, t)=0, T=T_{\infty}, c=c_{\infty} \text { for } t<0 \forall z \\
& u(0, t)=U_{0}\left[1+\frac{\varepsilon}{2}\left(e^{\mathrm{int}}+e^{-\mathrm{int}}\right)\right], T(0, t)=T_{w}, c(0, t)=c_{w} \\
& u(\infty, t) \rightarrow 0, T(\infty, t) \rightarrow T_{\infty}, c(\infty, t) \rightarrow c_{\infty}, \varepsilon<<1 \quad \text { for } t \geq 0
\end{aligned}
$$

Thermo-Physical properties are related as follows:

$$
\begin{gathered}
\rho_{n f}=(1-\phi) \rho_{f}+\phi \rho_{s}, \alpha_{n f}=\frac{k_{n f}}{\left(\rho c_{p}\right)_{n f}} \\
\left(\rho c_{p}\right)_{n f}=(1-\phi)\left(\rho c_{p}\right)_{f}+\phi\left(\rho c_{p}\right)_{s} \\
(\rho \beta)_{n f}=(1-\phi)(\rho \beta)_{f}+\phi(\rho \beta)_{s} \\
k_{n f}=k_{f}(1-\phi)+\beta_{1} k_{p} \phi+c_{1} \frac{d_{f}}{d_{p}} k_{p} \operatorname{Re}^{2} d_{p} p r \phi
\end{gathered}
$$

$$
\frac{\mu_{n f}}{\mu_{f}}=1+2.5 \phi+4.5\left(\frac{1}{\frac{h}{d_{p}}\left(2+\frac{h}{d_{p}}\right)\left(1+\frac{h}{d_{p}}\right)^{2}}\right)
$$

Where $\beta_{1}=0.01$ is a constant for considering the kapitza Resistance per unit area

$c_{1}=18 \times 10^{6}$ is proportionality constant

$\operatorname{Re} d_{p}=\frac{d_{p}}{\gamma_{f}} \frac{\kappa T}{3 \pi \mu_{f} d_{p} l_{f}}=\frac{1.381 \times 10^{23} T}{\gamma_{f} 3 \pi \mu_{f}(0.738)}$

$d_{f}=0.384 \mathrm{~nm}$ for water

$\operatorname{Pr}_{=}$Prandtl number $=\frac{\gamma_{f}}{\alpha_{f}}$

$l_{f}=$ Mean free path $=0.738$

$k=$ Boltzmann constant, $\mathrm{T}=300 \mathrm{k}$

We consider the solution of Esq. (1) as $\quad \mathrm{w}=-\mathrm{w}_{0}$

Thus, we introduce the following dimensionless variables:

$$
\begin{aligned}
& z=\left(\frac{\psi_{f}}{U_{0}}\right) Z, t=\left(\frac{\psi_{f}}{U_{0}^{2}}\right) t^{*}, n=\left(\frac{U_{0}^{2}}{\psi_{f}}\right) \eta, \\
& u=U U_{0}, \quad \theta=\frac{T-T_{\infty}}{T_{w}-T_{\infty}}, c=\frac{c-c_{\infty}}{c_{w}-c_{\infty}} \quad q_{r}=-\frac{4 \sigma_{1}}{3 \delta} \frac{\partial T^{4}}{\partial y}
\end{aligned}
$$

We assume that the temperature differences within the flow are sufficiently small so that the $T^{4}$ can be expressed as a linear function after using Taylor series to expand $T^{4}$ about the free stream temperature $T_{\infty}$ and neglecting higher-order terms. This result is the following approximation:

$$
T^{4} \cong 4 T_{\infty}^{3} T-3 T_{\infty}^{4}
$$

By using above, we obtain

$$
\frac{\partial q_{r}}{\partial z}=-\frac{16 \sigma_{1}}{3 \delta} \frac{\partial^{2} T^{4} T_{\infty}^{3}}{\partial z^{2}}
$$

Using equations $5,6,7,8$ the Equations $2,3 \& 4$ can be written in the following dimensionless form: 


$$
\begin{aligned}
& {\left[1-\phi+\phi\left(\frac{\rho_{s}}{\rho_{f}}\right)\right]\left(\frac{\partial U}{\partial \tau}-S \frac{\partial U}{\partial Z}\right)=1+2.5 \phi+4.5} \\
& \left(\frac{1}{\left(\frac{h}{d_{p}}\right)\left(2+\frac{h}{d_{p}}\right)\left(1+\frac{h}{d_{p}}\right)^{2}}\right) \frac{\partial^{2} U}{\partial Z^{2}}+\left[1-\phi+\phi \frac{\left(\rho \beta_{T}\right)_{s}}{\left(\rho \beta_{T}\right)_{f}}\right] \\
& \theta C \operatorname{os} \gamma+\left[1-\phi+\phi \frac{\left(\rho \beta_{c}\right)_{s}}{\left(\rho \beta_{c}\right)_{f}}\right] \frac{G_{c}}{G_{r}} C \operatorname{Cos} \gamma \\
& {\left[1-\phi+\phi \frac{\left(\rho c_{p}\right) s}{\left(\rho c_{p}\right) f}\right]\left(\frac{\partial \theta}{\partial \tau}-S \frac{\partial \theta}{\partial Z}\right)} \\
& =\frac{1}{p_{r}}\left(1-\phi+0.01 \phi \frac{k_{p}}{k_{f}}+\frac{k_{p}}{k_{f}^{2}} \phi \frac{\rho_{f}^{2} c_{p f}}{d_{p} \mu_{f}^{3}} 28632.9991 \times 10^{-52}\right) \frac{\partial^{2} \theta}{\partial Z^{2}} \\
& -\frac{1}{p_{r}} Q_{H} \theta+\frac{1}{p_{r}} \frac{4}{3} \frac{1}{R_{a}} \frac{\partial^{2} \theta}{\partial Z^{2}} \\
& \left(\frac{\partial c}{\partial \tau}-S \frac{\partial c}{\partial Z}\right)=\frac{1}{S c} \frac{\partial^{2} c}{\partial Z^{2}}+K C
\end{aligned}
$$

Where the corresponding boundary conditions (5) can be written in the dimensionless form as:

$$
\left.\begin{array}{l}
U(z, t)=0, \theta(z, t)=0, C(z, t)=0 \text { for } t<0 \forall z \\
U(0, t)=U_{0}\left[1+\frac{\varepsilon}{2}\left(e^{i n t}+e^{-i n t}\right)\right], \theta(0, t)=1, C(0, t)=1 \\
U(\infty, t) \rightarrow 0, \theta(\infty, t) \rightarrow 0, C(\infty, t) \rightarrow 0
\end{array}\right\} \forall t \geq 0
$$

Here $\operatorname{Pr}$ is the Prandtl number, $R_{a}$ is the Radiation parameter and $\mathrm{Q}_{\mathrm{H}}$ is the heat source parameter, $\mathrm{Sc}$ is the Schimdth number, $\mathrm{K}$ is the chemical Reaction parameter, $G r$ is the Grashof number, $G c$ is the Molecular Grashof number, which is defined as:

$$
\begin{aligned}
& p_{r}=\frac{\psi_{f}}{\alpha_{f}}, R_{a}=\frac{4 \alpha \sigma_{1} T_{\infty}^{3}}{\delta k_{n f}}, Q_{H}=\frac{Q \psi_{f}^{2}}{k_{f} U_{0}^{2}}, \\
& S c=\frac{\psi_{f}}{D_{n f}}, K=\frac{k_{l} \psi_{f}}{U_{0}^{2}}, \\
& \frac{G_{c}}{G_{r}}=\left(\frac{g \beta_{c f}\left(c_{w}-c_{\infty}\right) \gamma_{f}}{g \beta_{T f}\left(T_{w}-T_{\infty}\right) \gamma_{f}}\right)
\end{aligned}
$$

Where the velocity characteristic $U_{0}$ is defined as:

$$
U_{0}=\left[g \beta_{f}\left(T_{w}-T_{\infty}\right) \psi_{f}\right]^{1 / 3}
$$

The local Nusselt number $\mathrm{Nu}$ in dimension less form:

$$
N u=-\frac{k_{n f}}{k_{f}} \theta^{\prime}(0)
$$

\section{RESULTS AND DISCUSSIONS}

The governing equations are solved by using Method of lines with the help of Mathematica package and $\mathrm{Z}$ is limited to 6 . The variations of velocity $\mathrm{U}$, temperature $\theta$ and diffusion $\mathrm{C}$ are graphically exhibited. By keeping $\operatorname{Pr}=6.2, \mathrm{nt}=\pi / 2$ and $\varepsilon=$ 0.02 . The effects of various parameters are as follows.

The velocity increases with increase in volume fraction $(\phi)$ of the nano-fluid. It indicates the nano particle density dominates the motion of the solute more. It is exhibited in Fig.1 the variation of $\mathrm{U}$ with liquid like layer thickness (h) is exhibited in Fig. 2 the flow is resisted with increase in h. As the thickness increases the flow of the nano-fluid is very much decreasing. From Fig. 3 it is observed that the flow increases with particle size $\left(d_{p}\right)$. The friction among the liquid and the metal particles enhance the velocity. From Fig.4 the velocity decreases with increase in the inclination angle $(\gamma)$ of the plate. From Fig.5 the velocity decreases with increase in the heat source $\left(Q_{H}\right)$.There is no significant influence on the flow field by the moderate heat source. From Fig.6 it observed that the radiation parameter $\left(R_{a}\right)$ decreases the velocity. From Fig. 7 the increase in kinematic viscosity/decrease in diffusivity (Sc) decreases the velocity. From Fig. 8 the velocity increases from generative $(K<0)$ to destructive $(K>0)$ chemical reactions and found moderate for no reaction.

From Fig.9 it is observed that the increase in solid particles $(\phi)$ increases the temperature. Fig.10 exhibits the variation of temperature with size of the solid particle $\left(\mathrm{d}_{\mathrm{p}}\right)$. The temperature increases with increase in size of the particle. 
Fig.11 is temperature profile varying with heat source parameter $\left(Q_{H}\right)$. It found that the temperature decreases with increase in heat source. The increase in radiation parameter $\left(R_{a}\right)$ decreases temperature, it shown in Fig.12.The diffusivity decreases with increase in kinematic viscosity (Sc) from Fig. 13.The diffusivity increases with chemical reaction changes from generative to destructive from Fig.14.

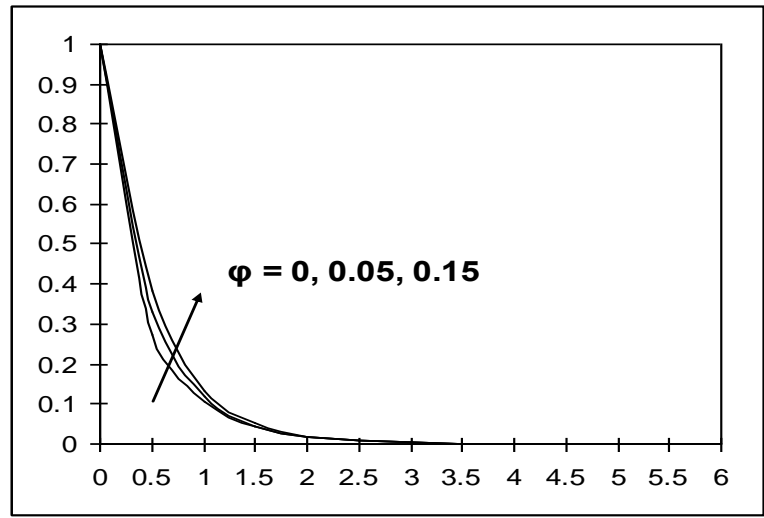

Fig.1 Variation of U with $\phi$

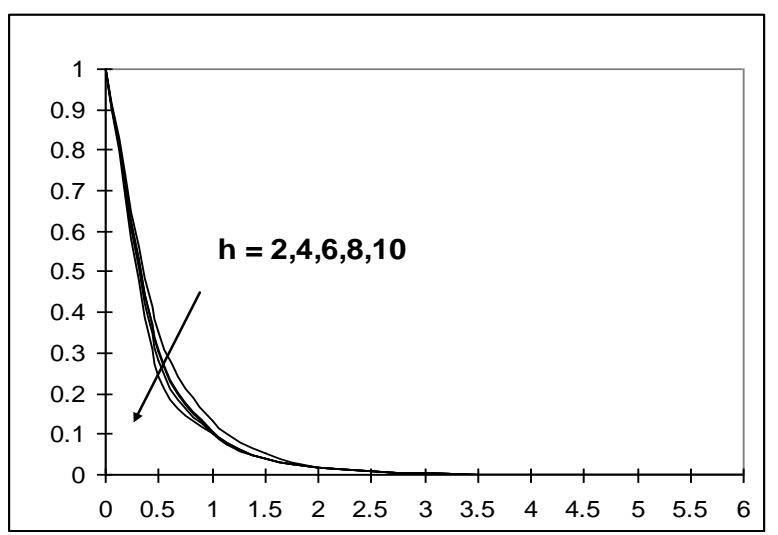

Fig.2 Variation of $U$ with $h$

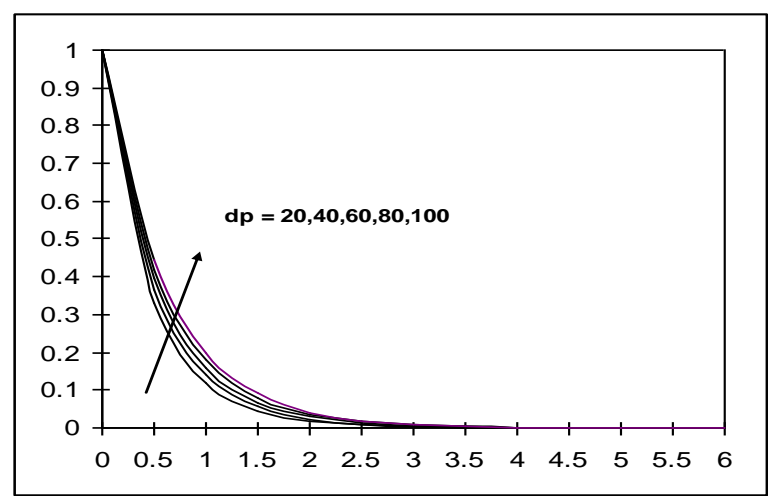

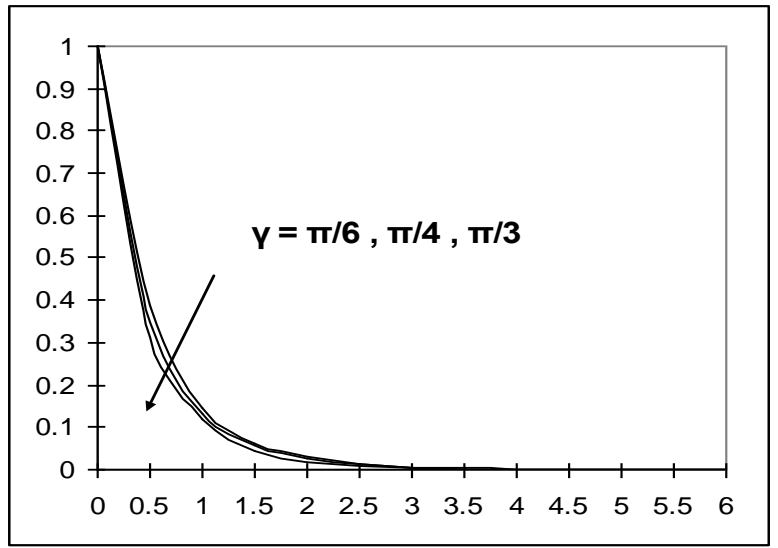

Fig.4 Variation of $U$ with $\gamma$

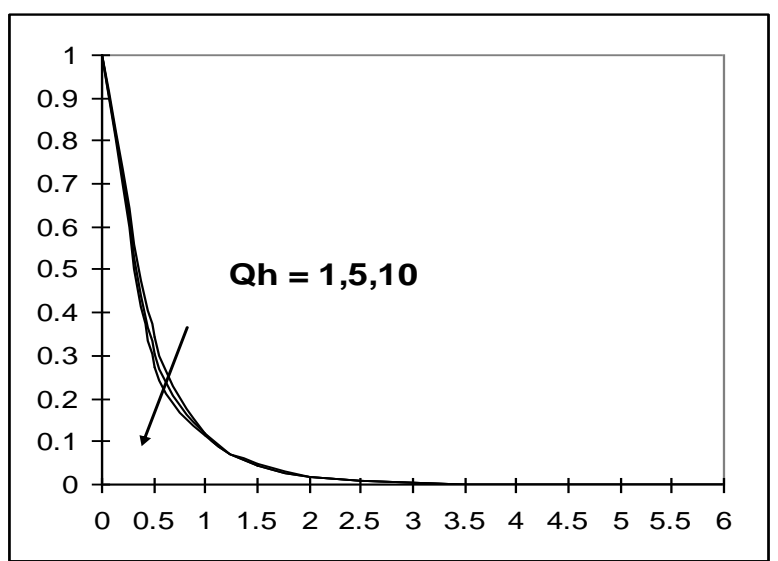

Fig.5 Variation of U with $Q_{H}$

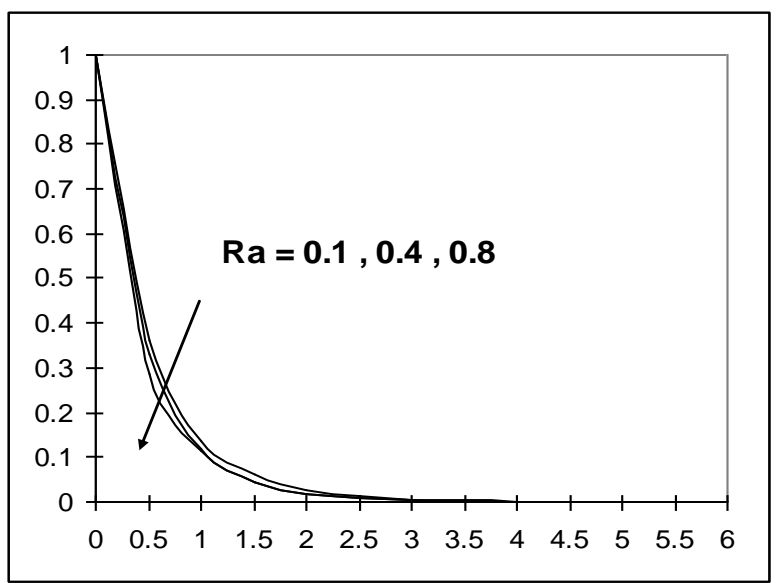

Fig.6 Variation of U with Ra

Fig.3 Variation of $\mathrm{U}$ with $d_{p}$ 


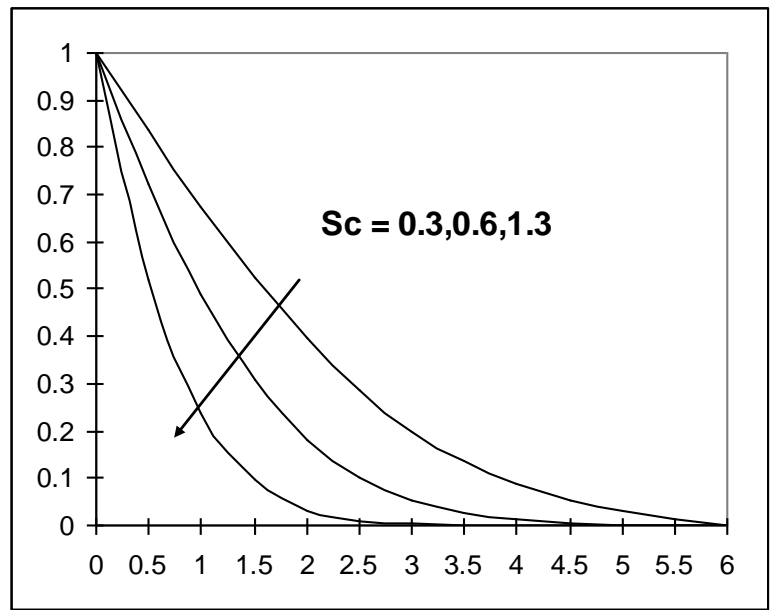

Fig.7 Variation of U with Sc

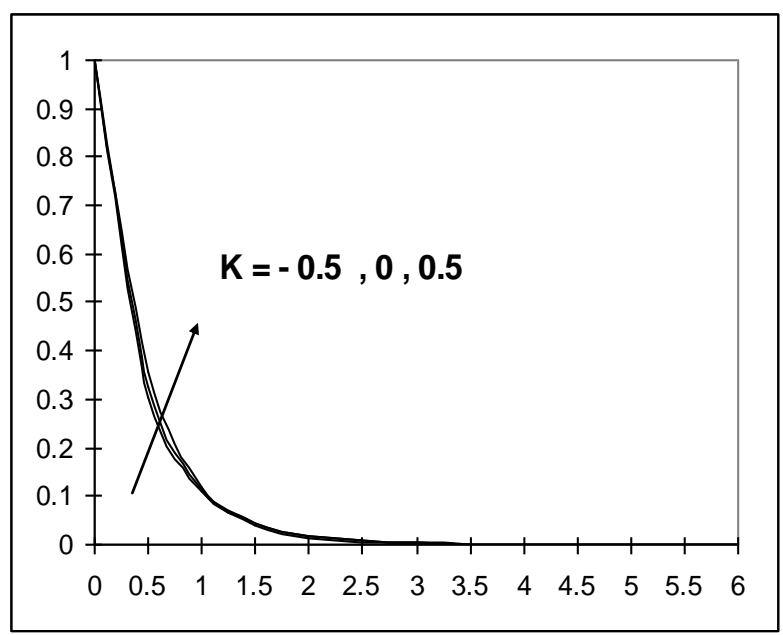

Fig.8 Variation of U with $\mathrm{K}$

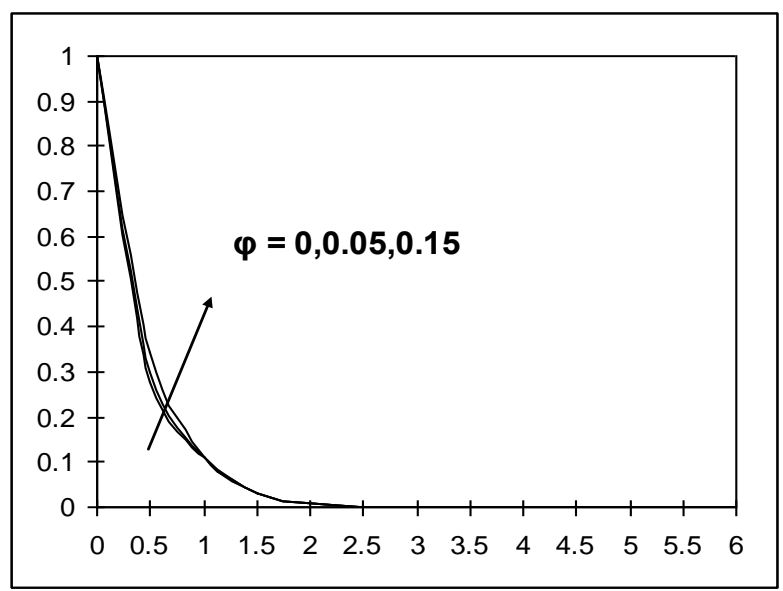

Fig.9 Variation of $\theta$ with $\phi$

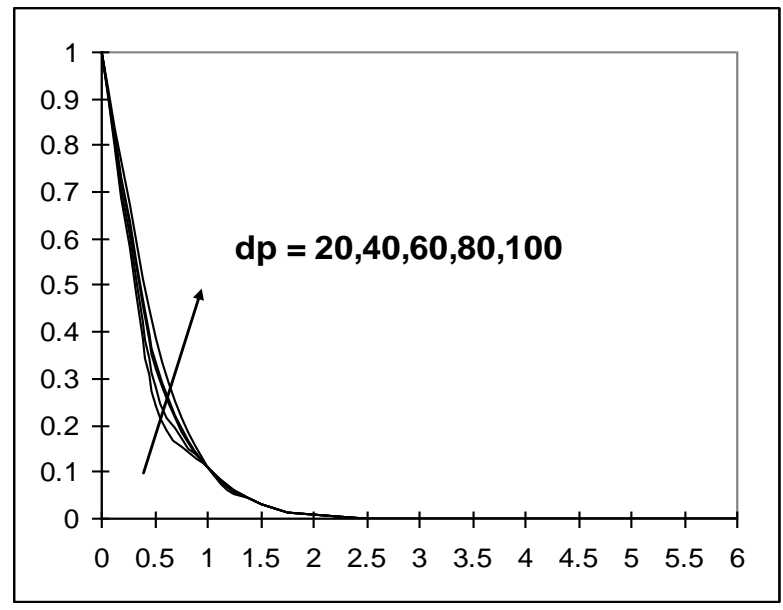

Fig.10 Variation of $\theta$ with $d_{p}$

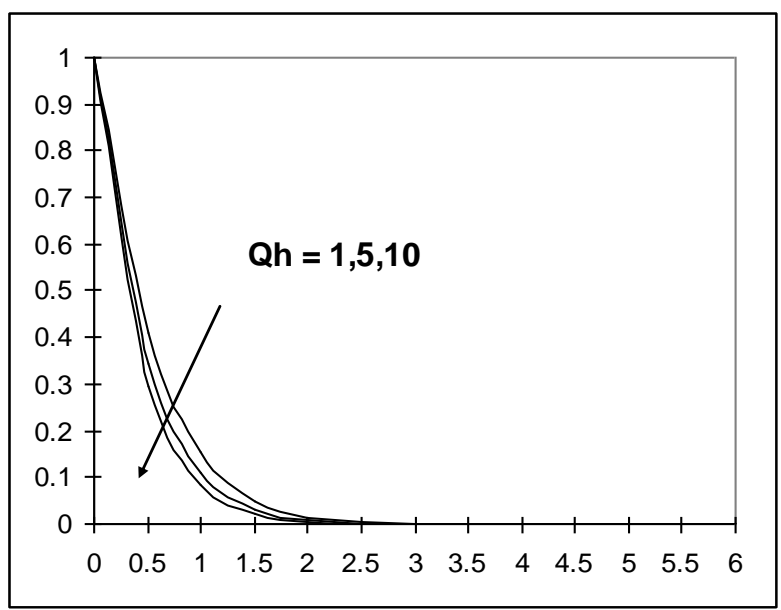

Fig.11 Variation of $\theta$ with $Q_{H}$

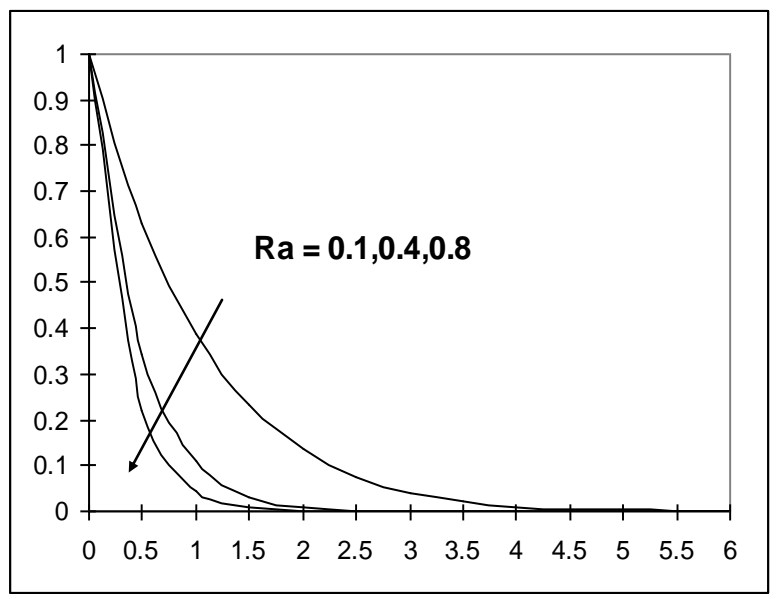

Fig.12 Variation of $\theta$ with $R_{a}$ 


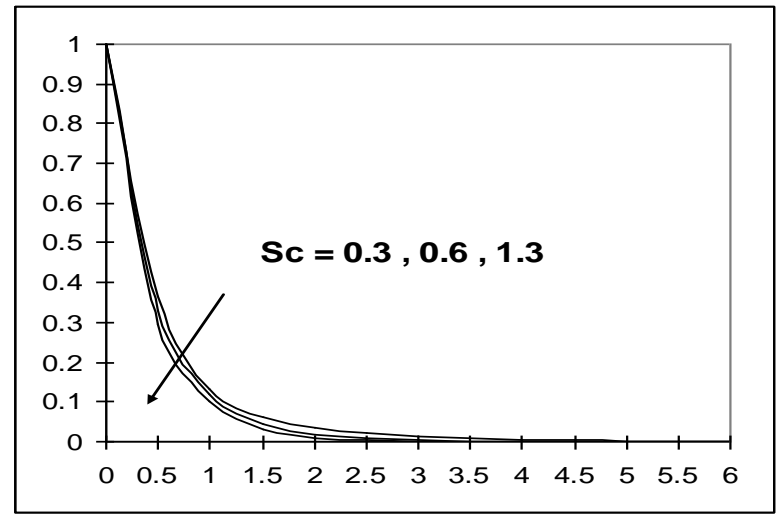

Fig.13 Variation of C with Sc

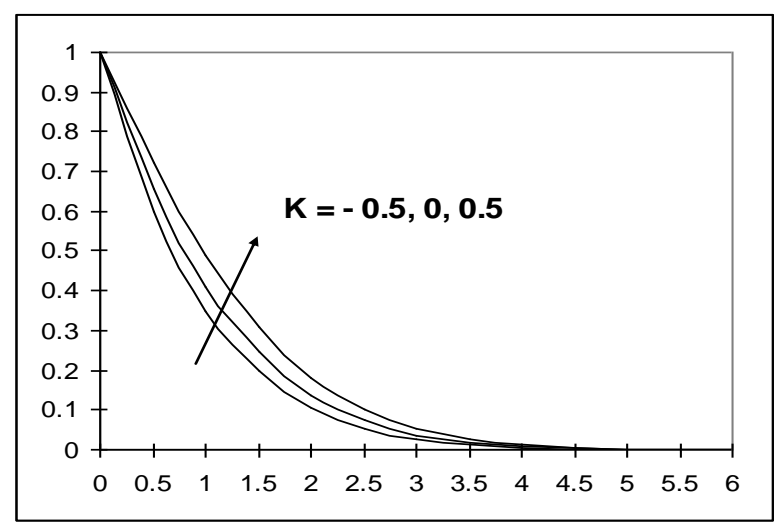

Fig.14 Variation of $\mathrm{C}$ with $\mathrm{K}$

\section{NUSSELLT NUMBER:}

The variation of rate of heat transfer coefficient for various volume fractions, size of the particle and heat source is displayed in Table -1 . The rate of heat transfer increases with increase in heat source for all volume fractions of the solid particles. But the rate of heat transfer is almost constant for low volume fractions for various sizes of the particle where as a significant enhancement of rate of heat transfer is observed for increase in size of the particle for higher volume fractions.

Table -1: Nussellt Number Values

$$
\gamma=\frac{\pi}{3}, S c=0.6, k=0.5
$$

\begin{tabular}{|l|l|l|l|l|l|}
\hline$\phi$ & $\begin{array}{l}Q_{H}=5 ; \\
\mathrm{d}_{\mathrm{p}}=20\end{array}$ & $\begin{array}{c}Q_{H}=5 ; \\
\mathrm{d}_{\mathrm{p}}=40\end{array}$ & $\begin{array}{c}Q_{H}=5 ; \\
\mathrm{d}_{\mathrm{p}}=100\end{array}$ & $\begin{array}{c}Q_{H}=1 ; \\
\mathrm{d}_{\mathrm{p}}=20\end{array}$ & $\begin{array}{l}Q_{H}=10 ; \\
\mathrm{d}_{\mathrm{p}}=20\end{array}$ \\
\hline 0.05 & 1.99986 & 1.99986 & 1.99984 & 1.56649 & 2.45631 \\
\hline 0.15 & 2.64386 & 2.64438 & 2.64439 & 2.05106 & 3.2664 \\
\hline
\end{tabular}

\section{REFERENCES}

[1]. M.I Anwar, I.Khan , S.Sharidan and M.Z.Salleh, Conjugate effets of heat and mass transfer of nano Fluids over a non- linear stretching sheet (2012) IJPS vol 7(26), pp 40814092.

[2]. Buongiorno J (2006) Convective transport in nano-fluids. ASME J Heat Transfer [128:240-250].

[3]. M. A. A. Hamad, I. Pop, Unsteady MHD free convection flow past a vertical permeable flat plate In a rotating frame of reference with constant heat source in a nano-fluid, Heat Mass Transfer (2011) [47:1517-1524].

[4]. Khan, W.A., A. Aziz (2011). Natural convection flow of a nano-fluid over a vertical plate with Uniform surface heat flux, International Journal of Thermal Sciences,[50: 12071214].

[5]. Kuznetsov AV, Nield DA (2010) Natural convective boundary layer flow of a nano-fluid past a vertical plate. Int J Therm Sci [288:243-247]

[6]. Sarit Kumar Das, Stephen U.S. CHOI , Hrishikesh E. Patel, Heat Transfer in Nano-fluids - A Review, Heat Transfer Engineering, [27(10):3-19, 2006].

[7]. Hyun Uk Kang,Wun-gwi Kim and Sung Hyun Kim, Effect of particle migration on the heat transfer of nanofluid (2007) Korea-Australia Rheology Journal Vol.19, No.3, November 2007 pp. 99-107

\section{BIOGRAPHIES}

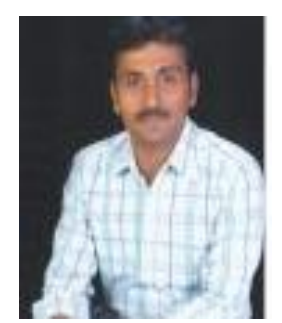

G.V.P.N.Srikanth working as an Assistant Professor in the Department of Mathematics, Guru Nanak Institute of Technology, Hyderabad. He received M.Sc degree in the stream of Mathematics from Andhra University in 2007, and pursuing Ph.D in the stream of convective Heat and Mass Transfer from JNTUH, Hyderabad, India.He has presented Research papers in National and International conferences and also published papers in International Journals. In the field of interest includes Fluid Dynamics, Heat and Mass Transfer. He is a Mathematician and logician. He received numerous honors and awards including the best teacher award.

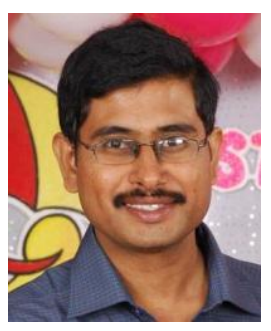

Dr.G.Srinivas working as Professor in the Department of Mathematics, Guru Nanak Institute of Technology, Hyderabad. He received his Ph.D from Sri Krishnadevaraya University, Anantapur in 2006. In the field of interest includes Fluid Dynamics, Heat and Mass Transfer. $\mathrm{He}$ is Mathematician, philanthropist. $\mathrm{He}$ made Numerous research presentations, organized and contributed paper sessions, and served as the reviewer at National and International conferences in Mathematics. He has supervised Research scholars for their 
Ph.D. His focus is helping, developing and implement a new teaching and learning framework.

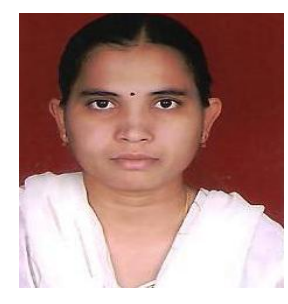

Dr.B.Tulasi Lakshmi Devi working as an Associate Professor in the Department of Mathematics, Guru Nanak Institute of Technology, Hyderabad. She received her Ph.D from Sri Krishnadevaraya University, Anantapur in 2011. In the field of interest includes Fluid Dynamics, Micro polar Fluds.

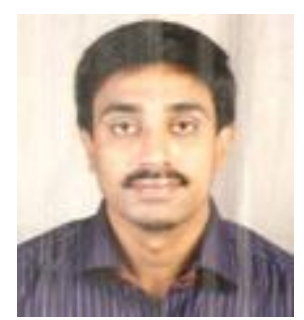

Dr.S.Sreenatha Reddy is Professor, orator, linguist and man of letter in the Department of Mechanical Engineering, Principal of Guru Nanak Institute of Technology. He received Ph.D from JNTUA, Annatapur. He took over a well organized institution, where he was able to hire the best staff and thus attract good quality students. Under his leadership the college roll grew leading to increased revenue from the government income from fee. He was skilled in managing in finance investments and equipped the workshops and laboratories with facilities far superior to those in any other technical college in India. He has supervised research projects. 